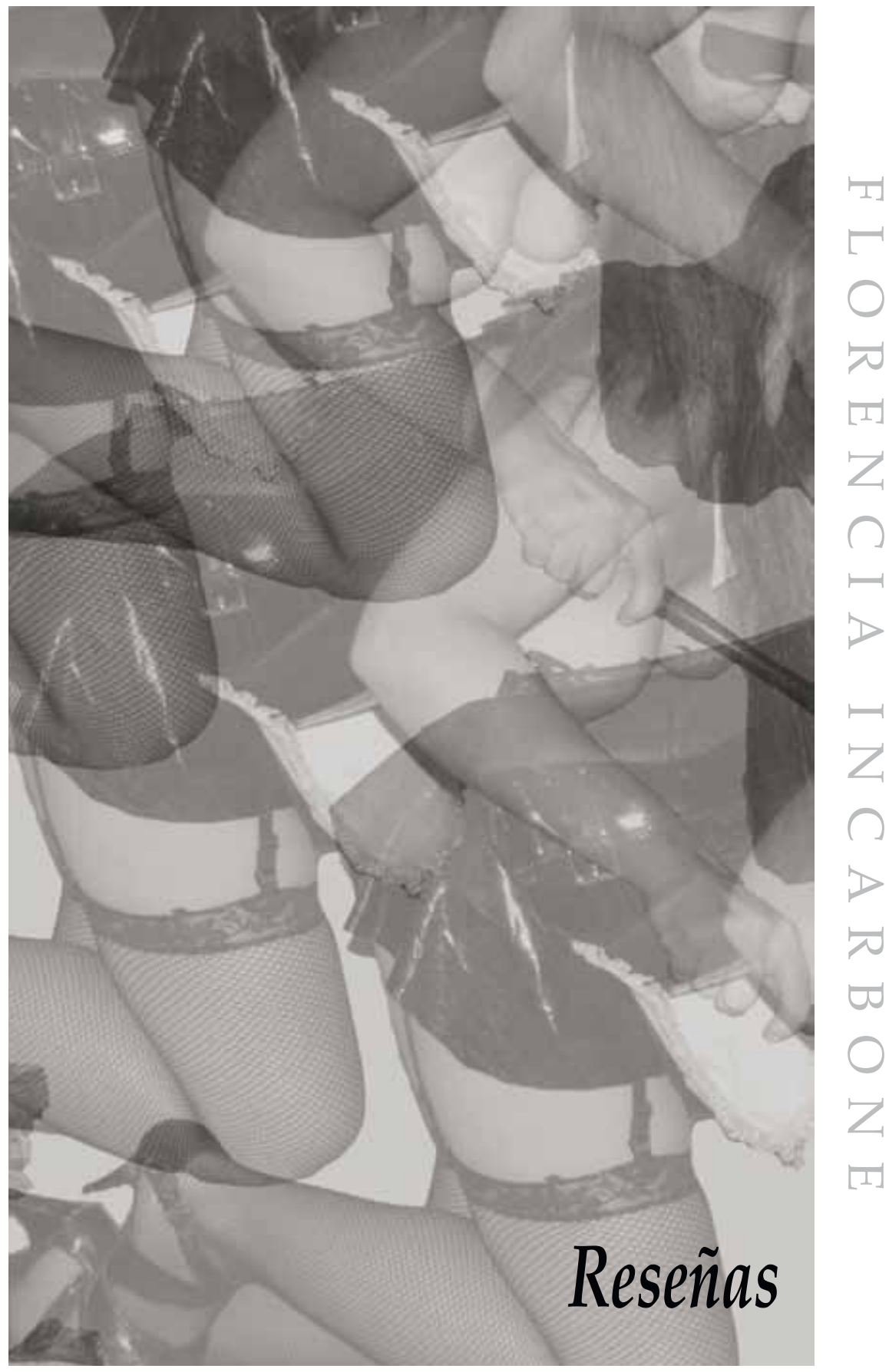




\title{
Ojo líquido de Guadalupe Santa Cruz Santiago en el parpadeo de la memoria
}

\author{
Elizabeth Collingwood-Selby \\ Universidad Metropoilitana de Ciencias de la Educación \\ ecollingwoodselby@gmail.com
}

I.

En días por venir las lectoras y lectores de Ojo líquido sostendrán para leerlo el libro abierto entre las manos. Lo harán con la naturalidad propia de quienes han vivido y crecido entre libros, de quienes, sin saber ya de su saber, saben demasiado bien qué tipo de objeto es ése que tienen entre las manos $\mathrm{y}$ ante los ojos. Expuestos los cuerpos al despliegue de signos sobre la página, se activará instantáneamente la maquinaria ancestral de su alfabetización; reconocerán las letras, las palabras, las frases, y quiéranlo o no, harán inmediatamente con ellas lo que ya, casi, no pueden dejar de hacer: antes de su encuentro con el ruido, con la mancha, antes del asombro y la extrañeza, dispuestos a destilar sentido, fa- bricarán el continente amplio o estrecho donde habrá de mover la escritura constreñida por el régimen de la comprensión.

El libro y los cuerpos que lo lean reclinados, acostados, de pie o sentados, sobre una silla, el asiento de una micro, el banco de una plaza, el suelo, un sofá, una cama, ocuparán algún lugar en el espacio más o menos poblado del planeta. Habrán llegado hasta allí después de un tránsito de años, tránsito cuyo particular recorrido será, en cada caso, diverso e irremontable; por más que lo intente, ninguno de ellos podrá recomponer con detalle el esquema cabal de sus desplazamientos. Habrán llegado hasta allí sin poder decir bien cómo. Transitados por los lugares por los que han transitado, esos cuerpos que leen serán también leídos por este "libro", tocados 
por una memoria cuyo desalineado crecimiento arruinará el mapa de la ciudad, de la lengua y del libro en que se encuentra escrito.

Si el cuerpo es, como sugiere Ojo líquido, "el larvado exceso de cruces" que en cada caso y en cada instante configura y precipita la memoria como pasaje y la memoria como paisaje que no puede fijarse para la posteridad en ninguna pose, entonces el cuerpo es lo que está en trance permanente de socavar la clausura que trabaja para contenerlo.

La Chimba, Quilicura, el río Mapocho, la Quebrada de Ramón, Costanera Norte, Barrio Matadero, Alameda, canal las Hornillas, Plaza Italia, Vivaceta, Cerro Navia, Cajón del Maipo, Pudahuel, cerro San Cristóbal, Tobalaba, Canal San Carlos, Vitacura, Zanjón de la Aguada, Ochagavía... nombres en el mapa de Santiago: barrios, cerros, calles, cursos de agua que en la superficie opaca o luminosa del plano aparecen y se conservan contemporáneos, tiesos, impermeables, intactos.

Auguste Blanqui, prisio. nero durante 37 años en el Fuerte de Taureau, escribió La eternidad por los astros desde su encierro y con ello logró, probablemente, abrir forados que le permitieron escapar, momentáneamente al menos, de su reclusión. En el capítulo VII de ese libro: "Análisis y síntesis del Universo" leemos:

\begin{abstract}
“Los sistemas planetarios no proporcionan en lo más mínimo, (...), un recorrido contemporáneo. Lejos de ello: sus edades se encabalgan y se entrecruzan en todos los sentidos $\mathrm{y}$ en todos los instantes, desde el momento del nacimiento encendido de la nebulosa hasta la muerte de la estrella, y hasta el choque que la resucite" (77).
\end{abstract}

Como en el sistema planetario de Blanqui, aquí, en Ojo líquido, parecen encabalgarse $\mathrm{y}$ entrecruzarse en todos los sentidos y en todos los instantes las edades de calles, cerros, cursos de agua, edificaciones, barrios y pasajes de Santiago cuyos nombres, arrancados del mapa por la escritura de los cuerpos que habitan, hacen memoria.

"Las fachadas espejeantes de Nueva Las Condes reflectan nada, demasiado altas para dar con el vacío de la desaparecida Villa San Luis, desalojada violentamente bajo la dictadura y violentamente derruida en la perspectiva de un megacentro (el alcalde de Las Condes al co- 
mando del combo que quitaba la primera piedra). Alojan hoy un conjunto de torres de oficinas cuya área central la conforma la Plaza de la Palabra" (Santa Cruz 34).

II.

“Jardín" es, en el libro de Guadalupe Santa Cruz, el nombre de una potencia vital y el nombre de un arruinamiento; nombre de lo que en la ciudad y en la lengua todavía crece y se expande sin ley, subvirtiendo en cada brote, la fibra gramatical de lo que hay.

Lo que hay está por todas partes sujeto al rigor de la línea que le sirve de guía, de soporte, de marco, de contención; en el espacio perfectamente delimitado que les impone, las cosas calzan con su propio principio y con su propio fin, son precisamente lo que son. La línea es el continuum que ha desterrado la historia heterogénea de su propia constitución. Rasgada y abierta, sin embargo, la línea es un ojo, un pasaje por el que se cuela la memoria líquida en la que lo que hay flota como resto en el flujo torrencial de lo posible.

Nutridos por la promiscuidad de esa memoria, abrién- dose paso entre un punto y otro, crecen con tendencias impredecibles, jardines de dimensión y especie diversa: troncos, ramas, hojas, semillas y flores a plena luz del día, y sombra de la noche.

En el medio predomi. nantemente selvático que habría sido "Santiago" antes de ser Santiago, probablemente asomaba por aquí y por allá una línea entrecortada. Hoy, en medio de las líneas que por todas partes repiten en la ciudad de Santiago el mapa de Santiago, interrumpiendo aquí y allá la tiesa expansión de las veredas, las calles, las casas, los edificios, los balcones, los baños, cocinas y habitaciones, asoman y crecen sin gobierno, solos o entrelazados, árboles, pastos, parras, flores, malezas, arbustos, hierbas, enredaderas: insistencia de una potencia selvática que sobreviviendo como jardín, o ya solo como pequeño brote en el terreno reducido de algún tiesto, expande y defiende el anacronismo de esa doble extinción.

"Los jardines son irreductibles, como un texto, no terminan de dar a ver su sentido porque nadie lo gobierna. Aunque una mano corrija, a veces, aquello que se encarama y tapa, que se 
come a otra planta, que no se da en esa ubicación. (...) Cuando el barrio es un secano (los bloques de departamentos crean sus perímetros de arena, zanjas para acentuar su apartamiento de la ciudad-bastidor) el jardín se concentra en tiestos repartidos por las zonas húmedas de la cocina y el baño" (Santa Cruz 28).

Ningún cuerpo, sugiere este libro, puede habitar el árido y aislante rigor de la línea donde lo que domina y persevera es la identidad ilocalizable del "se": se nace, se piensa, se hace, se dice, se escribe, se muere, sin falta, sin exceso, sin desmesura, sin jardín.

“'Se' no es todos, es nadie, nos ata 'se' sin juntarnos, basta de bastas hilvanadas entre todos al lugar. (...) 'Se' le quita el cuerpo a las palabras (para incandescencia de esos cuerpos, para fulgor de esas palabras), se mantienen a distancia para secreto del paisaje.

El nadie que habla, del verbo hablar, lo hace por la ley y sin cuerpo a cuerpo" (Santa Cruz 52)

"Jardín" no dice aquí lo que crece en los huecos húmedos de la ciudad y de la escritura bajo control y cálculo del paisajismo, sujeto al diseño cartográfico de un presente que administra lo que hay sin saber de la insistencia infiel de lo que hubo en el brote sin regulación de lo que habrá. "Jardín" dice aquí, en este libro, en la ciudad y en la lengua que lo cruza, el devenir del cuerpo, el pasaje de la memoria en el trance de su extinción.

"Tampoco es cosa de alguien, que hubiese una voluntad de levantar, de esclarecer un jardín, de lanzar algún diseño por sobre aquel pedazo de tierra y de imaginar en su aire las plantaciones ya crecidas, su tumulto verde, las arabescas que forman ramas y hojas en el volumen que ocupan entre la casa y las panderetas que deslindan con la vecindad. No, han de haber crecido las criaturas una por una, enredadas, haciéndose hueco, formando formas lentamente, corregido como un libro sin autor.

Los jardines permiten verificar la ignorancia de los mapas (...)" (Santa Cruz 21).

El mapa excluye todo lo que, como un jardín, crece en la ciudad por fuera del esquema bien delimitado de su contención. La batalla de la ciudad, de la lengua y del cuerpo por quebrar la línea de la clausura, por 
mantener abierto el ojo líquido de sus memorias es historia. Pero Historia es también la tendencia a la oclusión, clausura del nos-otros en el "se" que dibuja el mapa de una ciudad, de una lengua y de un cuerpo sin brote. Entre una y otra historia la ciudad, la lengua y el cuerpo parpadean.

Abierto sobre la mesa, el cuaderno de caligrafía tensa las paralelas sobre las que los niños, lápiz en mano, aprenden a calibrar la forma y el tamaño de las letras que trazan para transformarlas en signos reconocibles, para civilizar la anomalía de la mancha en el horizonte de la escritura. Después de constatar que las letras que dibuja no se dan en esa ubicación, que ninguna termina de calzar con su tamaño ni de ajustarse a la idea formal que se le impone como modelo, que siempre son demasiado grandes o demasiado pequeñas, que tiemblan con el temblor del cuerpo que las produce, la niña borra, escribe y vuelve a borrar, hasta que en alguna parte, el papel ennegrecido se hace polvo, la línea se rasga y la palabra, privada de soporte, se fuga para confundirse otra vez con la memoria material de las cosas; borrando, la niña cultiva la escritura como grabado y en el grabado, un cuerpo.

En el mapa de Santiago el Mapocho traza con sudor la línea sobre y bajo la que se inscribe, ordenada, la ciudad; en el cuerpo que la habita, el Mapocho es la línea que, rasgada por la insubordinación de su flujo líquido, desarregla esa compostura.

El libro tiene su lomo, columna vertebral, centro no escrito que sujeta y organiza de extremo a extremo la reunión de unas páginas que de otro modo se encontrarían sueltas. Arriba, abajo y por ambos costados, los márgenes blancos definen los límites dentro de los que se ubican, ordenados, los signos. Habituado a las dimensiones más o menos estandarizadas de esa parcelación, el cuerpo que lee recorre de izquierda a derecha el paisaje de marcas negras sobre fondo blanco en busca de su articulación. En ese recorrido el silabario, operando aun matricialmente como tabla de los elementos y catastro de combinaciones, somete al cuerpo entrenado a la lógica y al mecanismo primario de la composición. Pero el cuerpo es una compleja caja de resonancias que no puede controlar, sin más, los efectos de su lectura. Las palabras no reposan neutras entre margen y margen; crecen, decaen, se enredan, se despla- 
zan, se montan y desmontan de su futura comprensión; cada vez según la memoria de la erosionando con su caja en que resuenan.

“No sé escribir. Hago de lo que hay, dándose un lugar, jardines", leemos a pocas una lengua, una ciudad con páginas del comienzo de este memoria: un jardín, un cuerpo. libro tenazmente empeñado en socavar su propia estructura y escapar a la ley que de antemano prefigura su ordenamiento. Las letras, las palabras, las frases, todas fuera de sí, arrancadas del silabario y la gramática que alguna vez dispusieron el canon

\section{Referencias bibliográficas}

Blanqui, Auguste. La eternidad por los astros. Buenos Aires: Colihue, 2002.

Santa Cruz, Guadalupe. Ojo líquido. Santiago de Chile: Palinodia, 2011. 